\title{
Characterization of Salmonella Gallinarum from an outbreak in Raigarh, Chhattisgarh
}

\author{
Chandrahas Sannat ${ }^{1}$, Anil Patyal ${ }^{2}$, Nidhi Rawat ${ }^{1}$, R. C. Ghosh ${ }^{3}$, D. K. Jolhe ${ }^{3}$, R. K. Shende ${ }^{1}$, S. D. Hirpurkar ${ }^{1}$ and \\ Sanjay Shakya ${ }^{2}$
}

1. Department of Veterinary Microbiology, College of Veterinary Science \& Animal Husbandry, Chhattisgarh Kamdhenu Vishwavidyalaya, Anjora, Durg - 491001 , Chhattisgarh, India; 2. Department of Veterinary Public Health, College of Veterinary Science \& Animal Husbandry, Chhattisgarh Kamdhenu Vishwavidyalaya, Anjora, Durg - 491 001, Chhattisgarh,

India; 3. Department of Veterinary Pathology, College of Veterinary Science \& Animal Husbandry, Chhattisgarh Kamdhenu Vishwavidyalaya, Anjora, Durg - 491 001, Chhattisgarh, India.

Corresponding author: Chandrahas Sannat, e-mail: csannat@rediffmail.com,

Co-authors: AP: anilvet01@gmail.com, NR: dr_nidhirawat@yahoo.com, RCG: rcghosh@rediffmail.com, DKJ: djolhe@gmail.com, RKS: rshende786@rediffmail.com, SDH: smpuhir@yahoo.com, SS: drskshakya1@yahoo.co.in

Received: 15-08-2016, Accepted: 31-12-2016, Published online: 05-02-2017

doi: 10.14202/vetworld.2017.144-148 How to cite this article: Sannat C, Patyal A, Rawat N, Ghosh RC, Jolhe DK, Shende RK, Hirpurkar SD, Shakya S (2017) Characterization of Salmonella Gallinarum from an outbreak in Raigarh, Chhattisgarh, Veterinary World, 10(2): 144-148.

\begin{abstract}
Aim: The present investigation was conducted to isolate and characterize Salmonella Gallinarum from an outbreak of fowl typhoid in layer birds.

Materials and Methods: Clinically ill and dead layer birds from an outbreak were investigated. History, clinical signs, and postmortem lesions were suggestive of fowl typhoid. Postmortem samples including heart blood, intestinal contents, pieces of ovary, and liver were collected and processed immediately for bacterial culture, serotyping and antibiotic sensitivity tests. Isolates were further screened for the presence of extended spectrum beta lactamase (ESBL) $\left(b l a_{\mathrm{TEM}}\right)$ gene by polymerase chain reaction.

Results: On the basis of cultural, staining and biochemical characteristics; three bacterial isolates were confirmed as $S$. Gallinarum. On serotyping, somatic antigen O: 9 and 12 with nonflagellated antigen were detected in all three isolates. Isolates were intermediate sensitive to amoxycillin, amoxyclav, gentamicin and ciprofloxacin and resistant to most of the antibiotics including chloramphenicol, ampicillin, ceftazidime, cefexime, cefepime, azithromycin, nalidixin, tetracycline, oxytetracycline, and streptomycin. Two isolates were found to harbor ESBL $\left(b l a_{\text {TEM }}\right)$ gene.
\end{abstract}

Conclusion: Beta lactamase producer $S$. Gallinarum was confirmed as cause of increased mortality in layer birds during present investigation. Existence of multi drug resistant Salmonella poses serious threat to poultry industry in Chhattisgarh.

Keywords: $b l a_{\mathrm{TEM}}$, O: 9; 12 , poultry, Salmonella Gallinarum.

\section{Introduction}

Poultry industry is facing great setbacks due to frequent outbreaks of salmonellosis. Although many developed countries have eradicated these diseases from commercial poultry, it has increased incidence in most developing countries. Fowl typhoid caused by Salmonella Enterica subsp. Enterica serovar Gallinarum biovar Gallinarum (Salmonella Gallinarum), produces high mortality rates (up to $90 \%$ ) in birds of all ages, thus causing heavy economic loss [1]. Fowl typhoid has been reported from various parts of India including Kashmir [2], Haryana [3], Kerala [4], and Kolkata [5]; however, reports are lacking from Chhattisgarh state despite its high prevalence, which can be attributed to limited

Copyright: Sannat, et al. Open Access. This article is distributed under the terms of the Creative Commons Attribution 4.0 International License (http://creativecommons.org/licenses/ by/4.0/), which permits unrestricted use, distribution, and reproduction in any medium, provided you give appropriate credit to the original author(s) and the source, provide a link to the Creative Commons license, and indicate if changes were made. The Creative Commons Public Domain Dedication waiver (http:// creativecommons.org/publicdomain/zero/1.0/) applies to the data made available in this article, unless otherwise stated. diagnostic facilities under field conditions and under reporting.

Laboratory diagnosis of Salmonella relies on selection of suitable sampling procedure combined with a sensitive culture method and further confirmation by biochemical characteristics including IMViC pattern, sugar fermentation, and hydrogen sulfide production [5]. However, control of fowl typhoid is difficult due to lack of proper diagnosis and emergence of antibiotic resistance [6]. The prevalence of drug resistant gene $b l a_{\text {TEM }}$ type extended spectrum beta-lactamases (ESBLs) between Escherichia coli and Klebsiella has been frequently demonstrated in several countries but it is worth recognizing the emergence of ESBLs in Salmonella, which now confers serious clinical problem [7]. The determination of antibiotic susceptibility and multidrug resistance pattern of infectious organisms is therefore necessary to provide a vivid guide for veterinarians to make informed drug choices during the management and treatment of poultry diseases.

The present report sheds light on an outbreak of salmonellosis at Government Poultry Farm in 
Chhattisgarh (India) describing the disease diagnosis, agent characterization, and antibiotic resistance.

\section{Materials and Methods \\ Ethical approval}

No ethical approval was necessary to pursue this research work.

\section{Sample collection}

Increased mortality over a period of 3-week was reported in Giriraj and RIR adult layer birds of age groups 7-8 months at Government Poultry Farm, Raigarh, Chhattisgarh. Birds exhibited acute illness, high temperature, ruffled feather, difficulty in breathing, reduced feed intake, reluctance to move, and watery diarrhea. During postmortem examination, heart blood was collected aseptically from 10 birds in sterilized syringe. On postmortem examination, generalized tissue congestion and dark friable and coppery bronze colored enlarged liver were observed which were suggestive of fowl typhoid. Swab of heart and intestinal contents; tissue pieces of ovary and liver were collected at necropsy of all chickens for bacteriological examination.

\section{Bacterial isolation}

The samples were inoculated immediately in Rappaport Vassiliadis Soya (RVS) peptone broth for selective enrichment of Salmonella organisms and incubated at $37^{\circ} \mathrm{C}$ for $24 \mathrm{~h} \mathrm{[8]}$. After selective enrichment, one loopful of each RVS culture was streaked onto on to MacConkey lactose agar (MLA), brilliant green agar (BGA), xylose-lysine-deoxycholate (XLD) agar, and blood agar and incubated at $37^{\circ} \mathrm{C}$ for $24 \mathrm{~h}$. The nonlactose fermenting colonies of MLA were characterized microscopically using Gram's-stain.

\section{Biotyping}

Biochemical identification of bacterial isolates was done as described in OIE Manual of Diagnostic Tests and Vaccines for Terrestrial Animals, Volume 1 [8]. Briefly, the tests employed were catalase, oxidase, $\mathrm{O} / \mathrm{F}$ test, motility test using motility indole urea medium, reactions on triple sugar iron agar (TSI), urease, nitrate reduction, indole, methyl red (MR), Voges Proskauer (VP), citrate utilization, lysine decarboxylase, and sugar fermentation tests (i.e., glucose, sucrose and lactose with an inverted durham tube for acid and gas production, maltose, dulcitol and rhamnose fermentation). All the media used were procured from HiMedia.

\section{Serotyping}

The serotyping of Salmonella isolates was performed by National E. coli and Salmonella Typing Center, Central Research Institute, Kasauli, Himachal Pradesh.

\section{Antibiotic sensitivity test (ABST)}

The ABST was conducted by the disc diffusion method as per Bauer et al. [9] in Muller Hinton agar. Antimicrobial inhibition zone diameter was measured and categorized as susceptible, intermediate or resistant. Antibiotic discs (HiMedia) of widely used antimicrobials such as ciprofloxacin $(5 \mu \mathrm{g})$, cefixime $(5 \mu \mathrm{g})$, amoxyclav $(30 \mu \mathrm{g})$, ceftazidime $(30 \mu \mathrm{g})$, chloramphenicol $(30 \mu \mathrm{g})$, azithromycin $(15 \mu \mathrm{g})$, amoxycillin $(30 \mu \mathrm{g})$, ampicillin $(10 \mu \mathrm{g})$, cefepime $(30 \mu \mathrm{g})$, enrofloxacin $(10 \mu \mathrm{g})$, nalidixin $(30 \mu \mathrm{g})$, gentamicin $(10 \mu \mathrm{g})$, tetracycline $(30 \mu \mathrm{g})$, oxytetracycline $(30 \mu \mathrm{g})$, and streptomycin $(10 \mu \mathrm{g})$ were used.

\section{Detection of multidrug resistant gene}

Salmonella isolate was further screened for the presence of $b l a_{\mathrm{TEM}}$ gene by polymerase chain reaction (PCR) following the protocol described by Monstein et al. [10] with some modifications. For PCR, template DNA incorporated in reactions was prepared by boiling and snap chill method [11]. Purity and concentration of DNA was detected by $0.8 \%$ agarose gel electrophoresis and stored at $-20^{\circ} \mathrm{C}$. Recommended primer set of a $b l a_{\text {TEM }}$ forward primer: 5'- TCGCCGCATACACTATTCTCAGAA TGA -3 , and a bla $a_{\text {TEM }}$ reverse primer: 5'- ACGCTCACCGGCTCCAGATTTAT -3' were used to obtain a predicted product size of $445 \mathrm{bp}$ (Imperial Life Sciences (P) Limited, Gurgaon, Haryana, India). PCR reactions were performed in a total volume of $25 \mu 1$ containing $\times 10$ PCR buffer (Tris with $15 \mathrm{mM} \mathrm{MgCl}$ ), $250 \mu \mathrm{M}$ of each deoxyribonucleotide triphosphate, $10 \mathrm{pmol}$ of each gene-specific primers, $1 \mathrm{U}$ Taq polymerase and $3 \mu \mathrm{l}$ of template DNA. PCR amplification was done using thermocycler (Mastercycler, Eppendorf, Germany), and cycles were performed with initial denaturation of $95^{\circ} \mathrm{C}$ for $10 \mathrm{~min} ; 30$ cycles of denaturation at $94^{\circ} \mathrm{C}$ for $30 \mathrm{~s}$, annealing at $60^{\circ} \mathrm{C}$ for $30 \mathrm{~s}$, extension at $72^{\circ} \mathrm{C}$ for $2 \mathrm{~min}$, followed by a final extension step at $72^{\circ} \mathrm{C}$ for $10 \mathrm{~min}$. After the completion of reaction cycles, the amplified products were electrophoresed on $1.5 \%$ agarose gel stained with ethidium bromide $(0.5 \mu \mathrm{g} / \mathrm{ml})$. The images of ethidium bromide stained DNA bands were analyzed under ultraviolet transilluminator (Biometra) and digitized using a gel documentation system (Gel Doc ${ }^{\mathrm{TM}}$ XR, Biorad, USA). Reagents used in PCR were procured from Thermo Scientific (USA) and Bangalore Genei (India).

\section{Results}

\section{Cultural and staining characteristics of bacterial isolates}

Gram-staining revealed the presence of small rod shape Gram-negative bacteria arranged singly and in pair (Figure-1). RVS culture of heart blood, swab of heart, and intestinal contents showed two types of colony morphology; three isolates showed colorless, translucent, smooth and raised colonies on MLA, indicative of lactose non fermenter organisms and others produced pink color colonies indicative of lactose fermenter organisms (Figure-2). On BGA, nonlactose fermenter isolates produced light pink colony against a rose pink background and was non hemolytic on blood 
agar. On XLD agar, red colonies were produced initially after $24 \mathrm{~h}$ of incubation, which get blackened at center on prolonged incubation (Figure-3). Similarly, on TSI, the reaction occurred slowly with the production of gas and black color colonies. Cultural characteristics of above three isolates were suggestive of Salmonella organisms.

\section{Biochemical profile of bacterial isolates}

All three isolates were catalase negative, oxidase positive, fermentative, urease negative, lysine decarboxylase positive, indole negative, MR positive, VP negative, citrate utilization positive, and nonmotile. However, nonmotile organisms were considered to be either Salmonella Pullorum or S. Gallinarum. During the present investigation, all three isolates fermented glucose, dulcitol, maltose and lysine decarboxylase but not rhamnose, sucrose and lactose which confirmed biovar as $S$. Gallinarum.

\section{Salmonella serotype}

All three Salmonella isolates were serotyped as S. Gallinarum with somatic antigen O: 9 and 12 .

\section{Antibiogram of $\boldsymbol{S}$. Gallinarum}

Salmonella Gallinarum isolates were intermediate sensitive to amoxyclav, amoxycillin, gentamicin, ciprofloxacin and enrofloxacin however resistant to chloramphenicol, ampicillin, ceftazidime, cefexime, cefepime, azithromycin, nalidixin, tetracycline, oxytetracycline and streptomycin.

\section{ESBL $\boldsymbol{b l a}_{\text {TEM }}$ gene}

Two isolates of $S$. Gallinarum were found to harbor the drug resistant $b l a_{\mathrm{TEM}}$ gene having amplicon size of 445 bp (Figure-4).

\section{Discussion}

Salmonellosis is becoming serious problem in developing country like India since control measures are not efficient and also the climatic conditions favor the environmental spread of these organisms [12] which might lead to increased incidence of salmonellosis. Likewise present study, Kumari et al. [1], Ambily and Mini [4], and Dey et al. [5] also recorded increased mortality due to fowl typhoid. Clinical signs and gross pathology reported in present investigation corresponds with the findings of Kumari et al. [1] who also noticed swollen and congested liver with bronze discoloration in cases of fowl typhoid.

Since the isolation and correct identification of Salmonella are very crucial for the characterization, the colonies having typical cultural characteristics were selected as presumptive for Salmonella serovars. Cultural morphology on XLD, MLA and BGA was in accordance with the findings of Park et al. [13] and Ferdous et al. [14]. Differentiation of two nonmotile biovars, viz., $S$. Gallinarum and $S$. Pullorum done by specific sugar fermentation tests concurs with the report of Rahman et al. [15]. Biochemical reactions and antigenic formula reported during present investigation were classical findings of $S$. Gallinarum $[5,16]$.

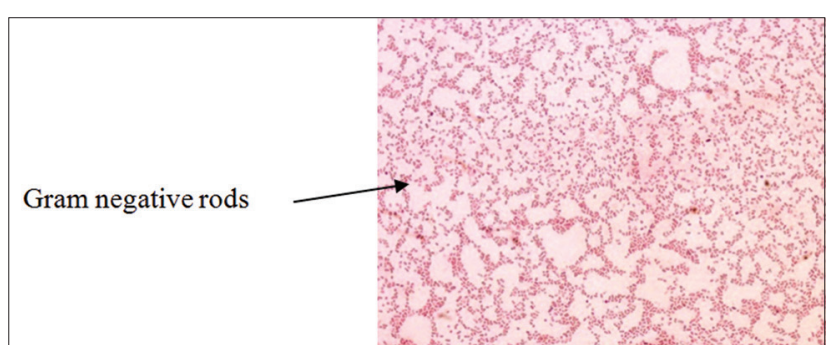

Figure-1: Gram-staining of Salmonella isolates.

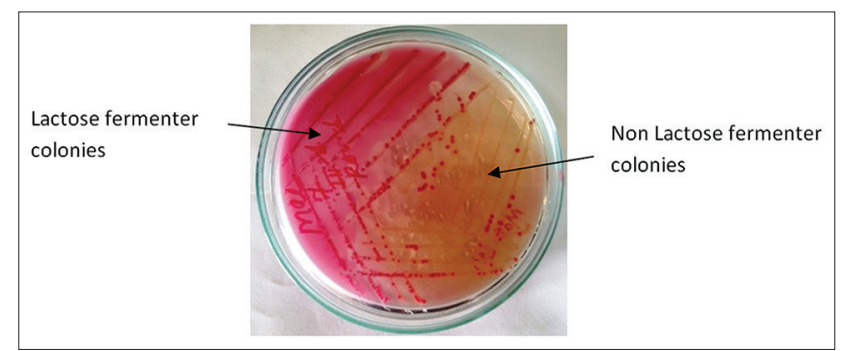

Figure-2: Salmonella colonies on MacConkey agar.

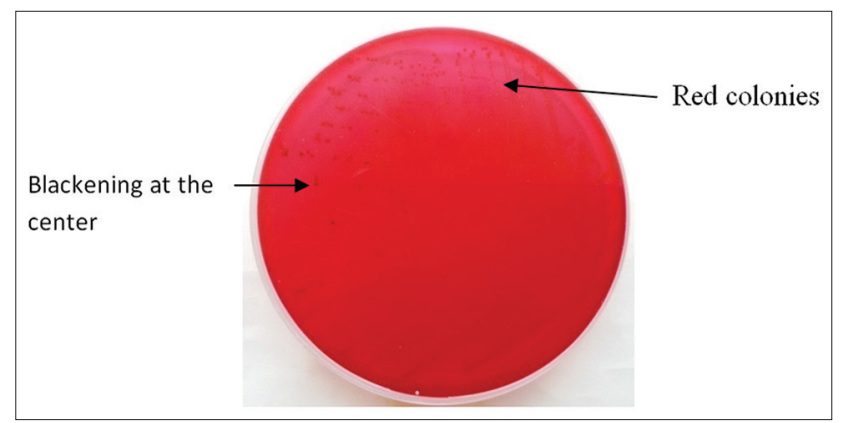

Figure-3: Salmonella colonies on xylose-lysine-deoxycholate agar.

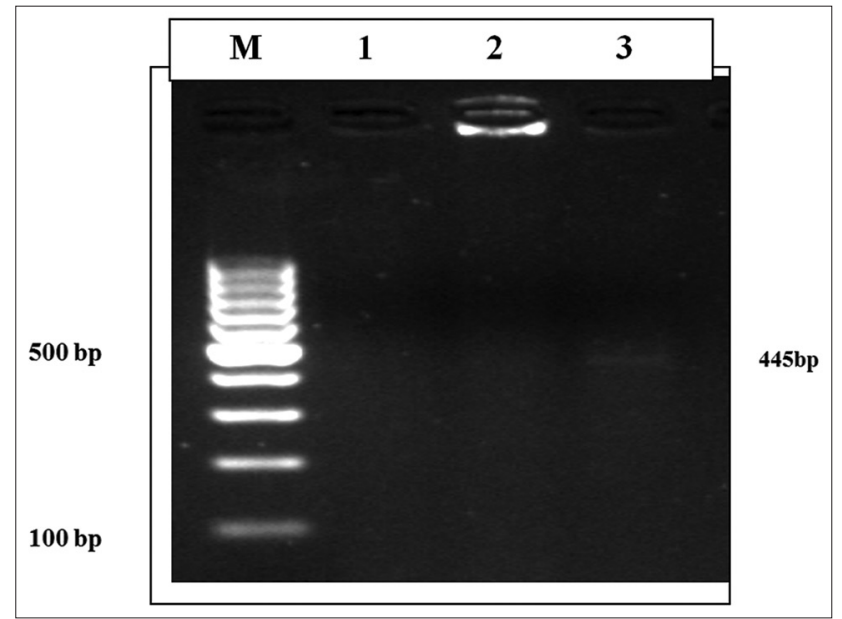

Figure-4: Agarose gel electrophoresis showing amplified polymerase chain reaction product of bla $a_{\text {TEM }}$ gene. Lane $\mathrm{M}$ : 100 bp DNA ladder, Lane 1, 2: Salmonella isolates with no amplicon, Lane 3: Salmonella Gallinarum isolate with bla TEM positive amplicon (445 bp).

The widespread and irrational use of antimicrobial drugs in poultry production has contributed to the emergence and maintenance of resistance genes particularly ESBLs genes, which poses serious threat 
not only to poultry industry but also of public health concern [17]. Similar to present findings, multidrug resistant Salmonella serovar were reported by Zafer Ata et al. [18] and Andoh et al. [19], whereas limited drug resistance in $S$. Gallinarum was observed by Dey et al. [5]. Likewise present study, Kumari et al. [1] reported $S$. Gallinarum isolates sensitive to ciprofloxacin, enrofloxacin and gentamicin, amoxicillin, amoxyclav, and resistant to nalidixic acid. Salmonella. Gallinarum isolates sensitive to ciprofloxacin and resistant to chloramphenicol were reported by Parvej et al. [20] and Ferdous et al. [14], respectively, which also concur our present finding. In contrast, Kumari et al. [1] reported reemergence of chloramphenicol sensitivity, and Filho et al. [6] reported reduced susceptibility of isolates to enrofloxacin, ciprofloxacin, norfloxacin, and ofloxacin. Emergence of ESBLs genes in salmonellae poses serious problem in management and treatment of salmonellosis in poultry [21,22]. In hormony with the present findings, earlier study also reported, $b l a_{\text {TЕM }}$ positive salmonellae isolates of poultry resistant to ampicillin [23]; amoxyclav, ampicillin and cefalothin [24] and nalidixic acid, chloramphenicol, tetracycline and trimethoprim [22].

\section{Conclusion}

ESBL producer $S$. Gallinarum was reported as the cause of increase mortality in layer birds at poultry farm of Chhattisgarh. Emergence of multidrug resistant Salmonella with ESBLs activity during this study pretense a serious threat for future treatment options in poultry industry in Chhattisgarh.

\section{Authors' Contributions}

CS designed the experiment under supervision of SDH. Postmortem examination was made by RCG and DKJ. Media preparation, sample collection and bacteriological analysis were performed by CS, NR and RKS. Molecular work was performed by AP and SS. All authors participated in draft and revision of the manuscript. All authors read and approved the final manuscript.

\section{Acknowledgments}

The authors are highly thankful to National E. coli and Salmonella Typing Center, Central Research Institute, Kasauli, Himachal Pradesh, for performing serotyping work during this study.

\section{Competing Interests}

The authors declare that they have no competing interests.

\section{References}

1. Kumari, D., Mishra, S.K. and Lather, D. (2013) Pathomicrobial studies on Salmonella Gallinarum infection in broiler chickens. Vet. World., 6(10): 725-729.

2. Nazir, S., Kamil, S.A., Darzi, M.M., Mir, M.S., Nazir, K. and Amar, A. (2012) Pathology of spontaneously occurring salmonellosis in commercial broiler chickens of Kashmir valley. J. World's Poult. Res., 2(4): 63-69.
3. Arora, D., Kumar, S., Singh, D., Jindal, N. and Mahajan, N. (2013) Isolation, characterization and antibiogram pattern of Salmonella from poultry in parts of Haryana. India. $A d v$. Anim. Vet. Sci., 1(5): 161-163.

4. Ambily, R. and Mini, M. (2014) Salmonellosis in Japanese quails - A report from central Kerala, India. Int. J. Sci. Res., 3: 361-363.

5. Dey, S., Mahanti, A., Batabyal, K., Joardar, S.N., Samanta, I., Isore, D.P. and Pakhira, M.C. (2016) Identification and antimicrobial susceptibility of Salmonella Gallinarum isolated from fowl typhoid outbreak in backyard Vanaraja fowl. Explor. Anim. Med. Res., 6(1): 63-67.

6. Filho, R.A.C., Ferreira, J.C., Kanashiro, A.M.I., Darini, A.L.D. and Junior, A.B. (2016) Antimicrobial susceptibility of Salmonella Gallinarum and Salmonella Pullorum isolated from ill poultry in Brazil. Cien. Rural, 46(3): 513-518.

7. Oghenevo, O., Bassey, B., Yhiler, N., Francis, U. and Angela, O. (2016) Antibiotic resistance in extended spectrum beta-lactamases (Esbls) Salmonella species isolated from patients with diarrhoea in Calabar, Nigeria. J. Clin. Infect. Dis. Pract., 1: 107.

8. OIE. (2012) Fowl typhoid and Pullorum disease. In: Manual of Diagnostic Tests and Vaccines for Terrestrial Animals. $7^{\text {th }}$ ed. Office International Des Epizooties, Paris. p1-14.

9. Bauer, A.W., Kirby, W.M.M., Shernis, J.C. and Turck, M. (1966) Antibiotic susceptibility testing by standardized single disc method. Am. J. Clin. Pathol., 45(4): 493-497.

10. Monstein, H.J., Ostholm Balkhed, A., Nilsson, M.V., Nilsson, M., Dornbusch, K. and Nilsson, L.E. (2007) Multiplex PCR amplification assay for the detection of blaSHV, blaTEM and blaCTX-M genes in Enterobacteriaceae. APMIS., 115(12): 1400-1408.

11. Nagappa, K., Tamuly, S., Brajmadhuri, Saxena, M.K. and Singh, S.P. (2007) Isolation of Salmonella Typhimurium from poultry eggs and meat of Tarai region of Uttaranchal. Indian J. Biotechnol., 6: 407-409.

12. Barrow, P.A. and Freitas Neto, O.C. (2011) Pullorum disease and fowl typhoid--new thoughts on old diseases: A review. Avian Pathol., 40(1): 1-13.

13. Park, S.H., Ryu, S. and Kang, D.H. (2012) Development of an improved selective and differential medium for isolation of Salmonella spp. J. Clin. Microbiol., 50(10): 3222-3226.

14. Ferdous, T.A., Lutful Kabir, S.M., Mansurul Amin, M. and Mahmud Hossain, K.M. (2013) Identification and antimicrobial susceptibility of Salmonella species isolated from washing and rinsed water of broilers in pluck shops. Int. J. Anim. Vet. Adv., 5(1): 1-8.

15. Rahman, B.A., Wasfy, M.O., Maksoud, M.A., Hanna, N., Dueger, E. and House, B. (2014) Multi-drug resistance and reduced susceptibility to ciprofloxacin among Salmonella Enterica serovar Typhi isolates from the Middle East and central Asia. New Microbes. New Infect., 2(4): 88-92.

16. Mir, I.A., Kashyap, S.K. and Maherchandani, S. (2015) Isolation, serotype diversity and antibiogram of Salmonella Enterica isolated from different species of poultry in India. Asian Pac. J. Trop. Biomed., 5(7): 561-567.

17. Liebana, E., Carattoli, A., Coque, T.M., Hasman, H., Magiorakos, A.P., Mevius, D., Poirel, L., SchuepbachRegula, G., Torneke, K., Torren-Edo, J., Torres, C. and Threlfall, J. (2013) Public health risks of enterobacterial isolates producing extended-spectrum beta-lactamases or AmpC beta-lactamases in food and food-producing animals: An EU perspective of epidemiology, analytical methods, risk factors, and control options. Clin. Infect. Dis. 56: 1030-1037.

18. Zafer Ata, Z., Dinç, G., Yibar, A., Müştak, H.K. and Şahan, O. (2015) Extended spectrum beta-lactamase activity and multidrug resistance of Salmonella serovars isolated from chicken carcasses from different regions of Turkey. Ankara Üniv. Vet. Fak. Derg., 62: 119-123.

19. Andoh, L.A., Dalsgaard, A., Obiri-Danso, K., Newman, M.J., Barco, L. and Olsen, J.E. (2016) Prevalence 
and antimicrobial resistance of Salmonella serovars isolated from poultry in Ghana. Epidemiol. Infect., 144(15): 3288-3299.

20. Parvej, M.S., Nazir, K.H.M., Rahman, M.B., Jahan, M., Khan, M.F.R. and Rahman, M. (2016) Prevalence and characterization of multi-drug resistant Salmonella Enterica serovar Gallinarum biovar Pullorum and Gallinarum from chicken. Vet. World, 9(1): 65-70.

21. Wu, H., Wang, Y., Wu, Y., Qiao, J., Li, H., Zheng, S., Xia, X., Cui, S., Wang, X., Xi, M., Meng, J. and Yang, B. (2015) Emergence of $\beta$-lactamases and extended-spectrum $\beta$-lactamases (ESBLs) producing Salmonella in retail raw chicken in China. Foodborne Pathog. Dis., 12(3): 228-234.
22. Abdel-Maksoud, M., Abdel-Khalek, R., El-Gendy, A., Gamal, R.F., Abdelhady, H.M. and House, B.L. (2015) Genetic characterisation of multidrug-resistant Salmonella Enterica serotypes isolated from poultry in Cairo, Egypt. Afr. J. Lab. Med., 4(1): 1-7.

23. Türkyılmaz, S., Hazımoğlu, Ş. and Bozdoğan, B. (2009) Antimicrobial susceptibility and resistance genes in Salmonella Enterica serovar enteritidis isolated from Turkeys. Isr. J. Vet. Med., 64(3): 72-77.

24. Lynne, A.M., Rhodes-Clark, B.S., Bliven, K., Zhao, S. and Foley, S.L. (2008) Antimicrobial resistance genes associated with Salmonella Enterica serovar newport isolates from food animals. Antimicrob. Agents Chemother., 52(1): 353-356.

$* * * * * * * *$ 